\title{
Radical radiotherapy in patients with cervix uteri carcinoma: experience of Ondokuz Mayis University
}

\author{
Alparslan Serarslan * Di Bilge Gursel, Deniz Meydan and Nilgun Ozbek Okumus
}

\begin{abstract}
Background: Radical radiotherapy is the standard treatment for patients with locally advanced cervix uteri carcinoma (FIGO stage IB2-IVA). Worldwide, incidence and mortality rates vary among regions because of differences in lifestyles and treatment standards. Herein, we evaluated the outcomes of radical radiotherapy in patients with locally advanced cervix uteri carcinoma from the middle Black Sea region of Turkey.

Methods: We retrospectively reviewed the records of 64 consecutive patients with locally advanced cervix uteri carcinoma who were treated from January 2013 to 2016 in our radiation oncology department. All patients staging and radiotherapy planning were performed with modern imaging techniques including magnetic resonance imaging and positron-emission-tomography/computed tomography before radical radiotherapy. Thereafter, all of them were treated with external beam radiotherapy and concurrent cis-platinum-based chemotherapy followed by three-dimensional intra-cavitary high-dose-rate brachytherapy.

Results: The median age at diagnosis was 54.5 years. The median follow-up period was 21 months. Acute grade 3 toxicity was detected in $3.1 \%$ of patients. Late toxicity was not detected in any patient. The 1- and 3-year progression-free survival rates were 83.6 and 67.5\%, respectively. The 1- and 3-year overall survival rates were 95.7 and $76.9 \%$, respectively. The most important prognostic factor was the FIGO stage. Distant metastasis was the most common cause of death in patients with locally advanced cervix uteri carcinoma despite radical radiotherapy.

Conclusions: In patients with locally-advanced cervix uteri carcinoma from the middle Black Sea region of our developing country, acceptable toxicity and survival rates are achieved similar to the recent literature from developed countries with using of modern staging, planning and radical radiotherapy techniques. However, recurrence was mostly in the form of distant metastases and further investigations on systemic therapies are required.
\end{abstract}

Keywords: Brachytherapy, Cervix cancer, Chemotherapy, Radiotherapy

\section{Background}

Cervix uteri carcinoma is the most common gynecological cancer worldwide. In addition, it is the fourth most common malignancy and the fourth leading cause of cancerrelated death in women. Incidence and death rates of cervix uteri carcinoma shows significant geographical variation $[1,2]$. In Turkey, cervix uteri carcinoma is the third most common gynecological cancer, after corpus uteri and ovarian carcinoma. In addition, it is the ninth most common malignancy in women [3]. Although the

\footnotetext{
* Correspondence: alparslanserarslan@hotmail.com

Department of Radiation Oncology, Faculty of Medicine, Ondokuz Mayis

University, Kurupelit, 55139, Atakum/Samsun, Turkey
}

incidence is slightly lower than that in western countries $(4.2$ vs. 7.1 per 100,000$)$, the mortality rate is slightly higher ( 1.8 vs. 1.6 per 100,000$)$ [4]. This variation may be due to religious, social, cultural, and economic differences.

Cervix uteri carcinoma is diagnosed mostly $(>80 \%)$ at the locally advanced stages [Fédération Internationale de Gynécologie et d'Obstétrique (FIGO) stage IB2-IVA and/or node-positive] in developing countries such as Turkey $[3,5]$. External beam radiotherapy (EBRT) with concurrent platinum-based chemotherapy (CHT) followed by brachytherapy (BRA), also known as radical radiotherapy

(c) The Author(s). 2019 Open Access This article is distributed under the terms of the Creative Commons Attribution 4.0 International License (http://creativecommons.org/licenses/by/4.0/), which permits unrestricted use, distribution, and 
(RT), is the standard treatment for locally advanced cervix uteri carcinoma (LACC), based on the results of fiverandomized-controlled trials [6-11].

No studies have explored the treatment outcomes of cervix uteri carcinoma in Turkey. The Radiation Oncology Department of Ondokuz Mayis University Hospital is the only center with a BRA device and treats LACC patients from the Black Sea region of Turkey. Therefore, we retrospectively analyzed radical RT outcomes in patients with LACC from the Black Sea region of Turkey.

\section{Methods}

\section{Ethics, consent and permissions}

This study was approved by the local Ethics Committee of Ondokuz Mayis University Hospital, Samsun, Turkey (acceptance date: 22/6/2017; and number: 2017/256), and all patients provided written inform consent.

\section{Patient evaluation}

A total of 64 patients with FIGO stage IB2-IVA and/or node metastasis positive $(\mathrm{N}+)$ cervix uteri carcinoma, treated with radical RT from January 2013 to December 2016, were included in this retrospective study. All patients were initially evaluated using abdominopelvic magnetic resonance imaging (MRI) and whole-body positron emission tomography-computed tomography (PET-CT). Patients with paraaortic lymph node metastasis were excluded from the study. All patients had normal hematological (white-blood-cell count, 3000-10,000/ $\mu$; hemoglobin, $>10 \mathrm{~g} / \mathrm{dl}$; platelet count, $\geq 100,000 / \mu \mathrm{l}$ ), renal (creatinine clearance $[\mathrm{CrCl}], \geq 60 \mathrm{ml} / \mathrm{min}$ ), and hepatic (bilirubin level, $\leq 1.5 \mathrm{mg} / \mathrm{dl}$; aspartate aminotransferase and alanine aminotransferase levels, $\leq 2.5 \times$ the upper limit of normal) function.

\section{Simulation}

EBRT and high dose rate (HDR)-BRA planning was performed three-dimensionally using a computed tomography (CT) simulator (Asteion Super 4; Toshiba Medical Systems, Otawara, Japan). Patients were immobilized in the supine position. CT imaging was under free breathing, full bladder, and empty rectum conditions at a slice thickness of $3 \mathrm{~mm}$. For the HDR-BRA procedure, a tandem ring (TR) applicator was used in conjunction with a rectal retractor. Additionally, a Foley's catheter was placed in the bladder and its balloon was filled with $7 \mathrm{ml}$ of diluted contrast media. Normal saline solution $(90 \mathrm{ml})$ plus $10 \mathrm{ml}$ of contrast medium was added to the bladder to determine the bladder volume for treatment planning. The datasets were transferred to a treatment planning system (TPS; Eclipse 8.6 for EBRT and 10.0 for HDRBRA; Varian Medical Systems, Palo Alto, CA, USA) via a digital imaging and communications in medicine (DICOM) network.

\section{Target volumes and delineation of organs at risk}

The gross tumor volume (GTV), clinical target volume (CTV), planning target volume (PTV), and organs at risk (OAR) were defined using individual axial CT slices. For the EBRT planning, CTV-1 included the GTV, corpus uteri, cervix uteri, common iliac, external iliac, internal iliac, obturator, and presacral lymph nodes, and at least $3 \mathrm{~cm}$ of the vaginal margin from the GTV. CTV-2 included the parametrium. PTV-1 and PTV-2 were defined as additional $1.5 \mathrm{~cm}$ and $1 \mathrm{~cm}$ margins around CTV-1 and CTV-2, respectively. PTV-total consisted of PTV-1 and PTV-2. For the HDR-BRA planning, Groupe Européen de Curiethérapie and the European Society for Radiotherapy and Oncology (GEC-ESTRO) recommendations were used to define the target volumes (e.g., high-risk CTV = HR-CTV). HR-CTV was delineated using individual axial CT slices based on post-EBRT MRI, and 3D conformational planning was used for BRA.

\section{External beam radiotherapy and concurrent chemotherapy}

The prescribed dose of EBRT to the PTV-total was 45$50.4 \mathrm{~Gy}$ in $25-28$ fractions for 5 to 5.5 weeks, using the three-dimensional (3-D) conformal RT (3D-CRT) technique (four-field) with $18 \mathrm{MV}$ photon energy with a linear accelerator (Clinac DHX; Varian Medical Systems, Palo Alto, CA, USA). The prescribed dose selection (45 or 50.4) was administered at the discretion of the treating physician. The aim of the target coverage was to deliver at least 95 and $100 \%$ of the prescribed dose to the PTV and CTV, respectively. The mean dose was constrained to <50 Gy for the rectum, with a maximum dose of $52 \mathrm{~Gy}$ for the small intestine, and of $60 \mathrm{~Gy}$ for the bladder. Concurrent CHT comprised $40 \mathrm{mg} / \mathrm{m}^{2} /$ day cisplatin (DDP) per week. The CHT was omitted if the white blood cell and neutrophil counts were below 3000 cells $/ \mu \mathrm{l}$ and $1500 / \mu \mathrm{l}$, respectively, or the platelet count was below 100,000/ $\mu$ l. Complete blood count, kidney, and liver functions were assessed twice a week, including once before CHT. The DDP dose was modified according to the weekly $\mathrm{CrCl}$ value. The DDP dose was reduced when $\mathrm{CrCl}$ was $<40 \mathrm{ml} / \mathrm{min}$ and administration was stopped when it was $<30 \mathrm{ml} / \mathrm{min}$.

\section{Brachytherapy}

After finishing EBRT, a dose of 5.5 Gy per fraction, in five fractions, was delivered to the HR-CTV by intracavitary HDR-BRA with an iridium-192 source using a BRA afterloader (GammaMedplus IX HDR Afterloader; Varian Medical Systems, Palo Alto, CA, USA), once a week under conscious sedation for all patients. The dose was constrained to $\mathrm{D}_{2 \mathrm{cc}}<75 \mathrm{~Gy}$ for the rectum, $<75 \mathrm{~Gy}$ for the sigmoid colon, and $<90 \mathrm{~Gy}$ for the bladder. 


\section{Follow-up}

After completing radical RT, initial tumor control was completed in all patients after 6 weeks of abdominopelvic MRI and 12 weeks of PET-CT. Thereafter, patients were followed-up at 3-month intervals for the first 2 years, biannually for years 2-5, and annually thereafter. Abdominopelvic MRI and cervical cytology were performed every 6 months for the first 5 years and annually thereafter. Early and late toxicity grading were performed according to toxicity criteria of the Radiation Therapy Oncology Group (RTOG) and the European Organization for Research and Treatment of Cancer (EORTC).

\section{End points and statistical analysis}

Local control, regional control, death from any cause or from disease, locoregional failure-free survival (LRFFS), distant metastasis-free survival (DMFS), progression-free survival (PFS), and overall survival (OS) were recorded and calculated. LRFFS was defined as the time between the date of diagnosis and the date of first local or regional relapse. DMFS was defined as the time between the date of diagnosis and the date of first distant metastasis. PFS was defined as the time between the date of diagnosis and the date of the first failure at any site. OS was defined as the time between the date of diagnosis and the date of death from any cause. FIGO stage, node metastasis, parametrial invasion, tumor size, initial tumor volume, size of HR-CTV, number of concurrent CHT course and D90 (EQD2) were potential factors affecting survival. Patient characteristics were described using descriptive statistics. The KaplanMeier method was used to analyze survival and the logrank test was used for univariate analysis. Multivariate Cox regression analysis was performed on the significant determinants identified by univariate analysis. A value of $P<0.05$ was considered statistically significant.

\section{Results}

\section{Patient clinical characteristics}

All 64 patients were from the Black Sea region of Turkey. The median age at diagnosis was $54.5 \pm 13.6$ years (range: $28-81$ years). The median weight was $71 \pm$ $13.7 \mathrm{~kg}$ (range: 48-94 kg). The histopathological diagnosis was squamous-cell carcinoma in 58 (90.6\%) patients. The FIGO stage was $2 \mathrm{~B}$ or higher in more than threequarters $(n=51 ; 79.5 \%)$ of the patients. Lymph node metastasis was present in 35 (54.6\%) patients (Table 1$)$. The median maximum diameter of the tumor was $5.1 \pm 1.4$ $\mathrm{cm}$ (range: $2.5-10 \mathrm{~cm}$ ). The median tumor volume was $64.5 \pm 56.1 \mathrm{~cm}^{3}$ (range: $6.3-310 \mathrm{~cm}^{3}$ ). Parametrial invasion was present in $50(78.1 \%)$ patients.

\section{Treatment}

The median time from diagnosis to EBRT was $32.5 \pm$ 21.6 days (range: 7-96 days). The EBRT dose was 45 Gy
Table 1 Clinical characteristics of the patients $(n=64)$

\begin{tabular}{lll}
\hline & Patients' number & $\%$ \\
\hline Histopathology & 58 & \\
Squamous cell carcinoma & 3 & 90.6 \\
Adenocarcinoma & 1 & 4.7 \\
Adeno-squamous cell carcinoma & 1 & 1.6 \\
Clear cell carcinoma & 1 & 1.6 \\
Small cell carcinoma & & 1.6 \\
FIGO Stage & 6 & \\
IB2 & 7 & 9.4 \\
IIA & 29 & 10.9 \\
IIB & 20 & 45.1 \\
III & 2 & 31.3 \\
IV & & 3.1 \\
Node metastasis & 29 & 45.4 \\
Negative & 35 & 54.6 \\
Positive &
\end{tabular}

FIGO Fédération Internationale de Gynécologie et d'Obstétrique

in $48(75 \%)$ patients and 50.4 in $16(25 \%)$ patients. All patients completed the planned EBRT. Of the 64 patients treated with weekly DDP, 45 (70.3\%) received five or more, and 13 (20.3\%) received between one and five, cycles. However, in six (9.4\%) patients, DDP was not administered due to high levels of blood creatinine or low $\mathrm{CrCl}$. BRA was applied to all patients.

\section{Dose-volume parameters}

The mean HR-CTV at the time of the first BRA was $31.56 \pm 13.15 \mathrm{~cm}^{3}$. The mean HR-CTV dose was $90.16 \pm$ 8.15 equivalent dose in 2 Gy (EQD2). The mean $\mathrm{D}_{2 \mathrm{cc}}$ dose for the rectum, sigmoid, and bladder was $65.51 \pm$ $7.02,63.37 \pm 8.79$, and 82.40 \pm 5.84 EQD2, respectively.

\section{Patterns of failure}

There were 12 (18.7\%) relapses in total; 4 (6.2\%) patients relapsed loco-regionally (local failure, $n=2$; regional failure, $n=1$; loco-regional failure, $n=1), 7$ (11\%) showed distant metastases, and 1 (1.5\%) showed both locoregional and distant metastasis. Two-thirds of metastases were in the lungs. Ten (15.6\%) patients had died by the end of the follow-up period. All deaths were due to cervix uteri carcinoma. The cause of death was localregional failure in two (3\%) patients and distant metastasis in the remaining eight $(12.6 \%)$ patients.

\section{Toxicity}

Acute gastrointestinal system (GIS) toxicity was grade 0 in $48(75 \%)$, grade 1 in $6(9.4 \%)$, and grade 2 in 10 (15.6\%) patients. Acute hematologic system toxicity was grade 0 in $44(68.8 \%)$, grade 1 in $4(6.3 \%)$, grade 2 in 14 
(21.9\%), and grade 3 in $2(3.1 \%)$ patients. Acute genitourinary system (GUS) toxicity was not detected. Acute (grade 4 or higher) and late toxicity were not detected in any patients.

\section{Survival}

After a median follow-up period of 21 months (range: 3-60 months), 54 (84\%) patients were alive. The 1- and 3 -year LRFFS rates were 96 and 87\%, respectively. The 1- and 3-year DMFS rates were 94.4 and $76 \%$, respectively. The 1- and 3-year PFS rates were 83.6 and $67.5 \%$, respectively. The 1- and 3-year OS rates were 95.7 and $76.9 \%$, respectively.

\section{Prognostic factors}

In the univariate analysis, significant prognostic factors for LRFFS included FIGO stage $(P=0.003)$ and D90 (EQD2) dose $(P=0.01)$. The 3-year LRFFS rate according to FIGO stage $\leq$ IIA, IIB, III, and IV was 100, 95, 71.3 , and $50 \%$, respectively. The 3 -year LRFFS rate according to a D90 (EQD2) dose $\leq 90$ Gy and $>90$ Gy was 65 and $100 \%$, respectively. In addition, significant prognostic factors for PFS and OS included FIGO stage $(P=$ 0.01 and $P=0.03$, respectively) and lymph node status $(P=0.008$ and $P=0.001$, respectively). The 3 -year PFS rate according to FIGO stage $\leq$ IIA, IIB, III, and IV was $100,75.9,46$, and $50 \%$, respectively. The 3 -year PFS rate according to lymph node status, i.e., node-negative versus pelvic node-positive, was 79.2 and $73.1 \%$, respectively. The 3-year OS rate according to FIGO stage $\leq$ IIA, IIB, and III was $100,88.1$, and $52.6 \%$, respectively. The 3 -year OS rate according to lymph node status, i.e., node-negative versus pelvic node-positive, was 91.7 and $74.6 \%$, respectively (Table 2 ). In the multivariate analysis, the only significant prognostic factor for LRFFS, PFS, and OS was the FIGO stage $(P=0.04, P=0.01$, and $P=$ 0.02 , respectively) (Table 3 ). In both univariate and multivariate analysis, no prognostic factor was found for DMFS.

\section{Discussion}

Radical RT in patients with cervix uteri carcinoma continues to improve with rapid developments in pretreatment (staging) and treatment-related imaging technologies. Each patient should be accurately staged so that the appropriate treatment can be performed. Accurate staging improves local control and survival, while reducing morbidity and the failure associated with unnecessary radiation doses and inadequate irradiation, respectively [12]. Currently, FIGO staging serves as a clinical evaluation system. Clinical staging accuracy decreases with increasing stage (from 85 to 21\%) [13]. Thus, where available, FIGO recommends crosssectional imaging techniques. Although staging of cervix
Table 2 Three-years survival rates of univariate analysis according to the prognostic factors

\begin{tabular}{|c|c|c|c|c|c|c|c|c|}
\hline & \multicolumn{2}{|c|}{ LRFFS } & \multicolumn{2}{|c|}{ DMFS } & \multicolumn{2}{|l|}{ PFS } & \multicolumn{2}{|l|}{ OS } \\
\hline & $\%$ & $P$ & $\%$ & $P$ & $\%$ & $P$ & $\%$ & $P$ \\
\hline FIGO stage & & 0.003 & & 0.26 & & 0.01 & & 0.03 \\
\hline$\leq \| \mathrm{A}$ & 100 & & 100 & & 100 & & 100 & \\
\hline$\| B$ & 95.0 & & 75.9 & & 75.9 & & 88.1 & \\
\hline III & 71.3 & & 65.0 & & 46.0 & & 52.6 & \\
\hline IV & 50.0 & & 100 & & 50.0 & & 100 & \\
\hline Node metastasis & & 0.42 & & 0.15 & & 0.14 & & 0.09 \\
\hline Negative & 95.2 & & 83.3 & & 79.2 & & 91.7 & \\
\hline Positive & 79.2 & & 69.7 & & 57.8 & & 65.9 & \\
\hline Parametrial invasion & & 0.95 & & 0.42 & & 0.60 & & 0.84 \\
\hline Positive & 92.1 & & 71.7 & & 68.2 & & 73.5 & \\
\hline Negative & 75.0 & & 90.9 & & 68.1 & & 88.9 & \\
\hline Tumor size & & 0.94 & & 0.19 & & 0.08 & & 0.11 \\
\hline$\leq 5 \mathrm{~cm}$ & 90.0 & & 80.6 & & 71.7 & & 79.2 & \\
\hline$>5 \mathrm{~cm}$ & 84.1 & & 68.0 & & 61.0 & & 56.8 & \\
\hline Initial tumor volume & & 0.39 & & 0.76 & & 0.32 & & 0.53 \\
\hline$<65 \mathrm{~cm}^{3}$ & 86.5 & & 75.7 & & 67.3 & & 62.4 & \\
\hline$\geq 65 \mathrm{~cm}^{3}$ & 88.4 & & 77.3 & & 67.7 & & 63.7 & \\
\hline HR-CTV & & 0.18 & & 0.39 & & 0.06 & & 0.12 \\
\hline$\leq 30 \mathrm{~cm}^{3}$ & 95.2 & & 81.7 & & 81.7 & & 84.6 & \\
\hline$>30 \mathrm{~cm}^{3}$ & 75.9 & & 68.8 & & 49.6 & & 70.0 & \\
\hline Chemothrapy & & 0.34 & & 0.77 & & 0.64 & & 0.82 \\
\hline$\leq 4$ course & 74.3 & & 71.1 & & 49.5 & & 87.5 & \\
\hline$\geq 5$ course & 94.4 & & 78.2 & & 76.2 & & 73.9 & \\
\hline D90 (EQD2) & & 0.01 & & 0.95 & & 0.23 & & 0.17 \\
\hline$\leq 90 \mathrm{~Gy}$ & 65.0 & & 67.7 & & 41.4 & & 72.9 & \\
\hline$>90 \mathrm{~Gy}$ & 100 & & 78.6 & & 78.6 & & 80.2 & \\
\hline
\end{tabular}

LRFFS loco-regional failure-free survival, PFS progression-free survival, DMSF distant metastasis-free survival, OS overall survival, FIGO Fédération Internationale de Gynécologie et d'Obstétrique, HR-CTV High risk clinical target volume

uteri carcinoma patients with CT is superior to clinical assessment, CT is less effective than both MRI and PETCT $[14,15]$. MRI is the best imaging technique for evaluating the invasion of primary tumor, showing high sensitivity (71-100\%), specificity (88-91\%), and negative

Table 3 Multivariate analysis for survivals

\begin{tabular}{lllll}
\hline & LRFFS & DMFS & PFS & OS \\
\hline FIGO Stage & 0.04 & 0.09 & 0.01 & 0.02 \\
Lymph node metastasis & 0.29 & 0.63 & 0.56 & 0.67 \\
High Risk CTV volume & 0.19 & 0.70 & 0.57 & 0.52 \\
D90 (EQD2) & 0.93 & 0.85 & 0.60 & 0.60
\end{tabular}

LRFFS loco-regional failure-free survival, PFS progression-free survival, DMFS distant metastasis-free survival, OS overall survival 
predictive value (100\%) [13]. However, PET-CT is superior to MRI for evaluating nodal involvement, showing high sensitivity $(79-84 \%$ vs. $56-72 \%)$ and specificity (95-99\% vs. 90-96\%). In addition, PET-CT prompts changes in the RT field and treatment plan in 34 and $23 \%$ of patients, respectively. For these reasons, FIGO and the National Comprehensive Cancer Network (NCCN) recommend both MRI and PET-CT for pretreatment evaluation of cervix uteri carcinoma [12, 13]. In our study, all patients were imaged for staging and planning with both MRI and PET-CT before RT.

EBRT in patients with LACC is used to reduce the macroscopic tumor volume and eradicate subclinical disease, with acceptable toxicity. Currently, the optimal RT technique remains unknown. The $3 \mathrm{D}-\mathrm{CRT}$ modality is commonly used and considered the gold standard in patients with LACC [16]. However, 3D-CRT pelvic fourfield RT causes significant and acute toxicity in GIS and GUS, and in hematologic systems, which interrupts RT $[17,18]$. Thus, the duration of RT is prolonged and the prognosis is negatively affected. For this reason, the clinical use of IMRT in patients with LACC has increased, especially during the last decade due to the known dosimetric advantages [19]. Currently, there are a limited number of clinical trials comparing the outcomes of IMRT and 3D-CRT usage in patients with LACC. Kidd et al. [20] and Yu et al. [21] reported significantly reduced acute grade 3 or higher treatment-related GI toxicity in their retrospective analyses of clinical results in patients with LACC treated with IMRT compared to the $3 \mathrm{D}-\mathrm{CRT}$ technique ( $6 \%$ vs. $17 \%, p=0.0017$; and $5 \%$ vs. $30 \%, p<0.05$, respectively). However, unlike $\mathrm{Yu}$ et al. [21], Kidd et al. [20] reported a survival advantage with IMRT compared to the 3D-CRT technique. In addition, two randomized prospective studies, by Gandhi et al. [22] and Naik et al. [17], reported that IMRT reduced acute grade 3 or higher treatment-related GI toxicity ( $4.5 \%$ vs. $27.3 \%, p=0.04 ; 5 \%$ vs. $20 \%, p=0.004$ ) without any survival advantage in patients with LACC. In our study, all of the patients were treated with $3 \mathrm{D}$ conformal EBRT, any grade 3 or higher treatment related toxicity was not observed both in GIS and GUS.

CHT is administered concurrently with RT to increase radiosensitivity. Although various concurrent $\mathrm{CHT}$ regimens have been used, the administration of DDP \pm fluorouracil (FU) is now the recommended regimen, in accordance with the results of five randomized trials. In those trials, DDP was administered via the intravenous bolus route, weekly $\left(40 \mathrm{mg} / \mathrm{m}^{2}\right)$, triweekly $\left(70-75 \mathrm{mg} / \mathrm{m}^{2}\right)$, or every 4 weeks $\left(50 \mathrm{mg} / \mathrm{m}^{2}\right)$ [7-11]. Based on both randomized and retrospective trials, weekly DDP administration has been recommended due to similar survival rates versus other regimens but with fewer side-effects [23-25]. Although carboplatin (weekly; AUC 2) is recommended in patients who cannot be administered DDP, survival rates and tumor responses are lower than for DDP [26]. In our study, concurrent chemotherapeutic agent was DDP and administered $40 \mathrm{mg}$ per square meter once a week to all patients, as recommended.

BRA is an integral part of radical RT in patients with LACC, and delivers high (> $80 \mathrm{~Gy}$ ) radiation doses to the tumor, while sparing the OAR [27]. As with EBRT, there has been an improvement in image-guidance techniques, treatment planning technologies, and application systems over the last two decades. Image guidance techniques in BRA are two-dimensional (2-D) with plain-radiography, two and a half dimensional (2.5-D) with ultrasonography (USG) [28], and 3-D with CT and MRI. The 2-D BRA technique is considered the conventional technique, and is based on two points representing doses to the paracervical triangle (Point A) and pelvic wall (Point B), in accordance with the Manchester system. Worldwide, 2-D treatment has been the most commonly used modality over the last decade, because it can be applied in the BRA room and is inexpensive, easy to use, and does not require extensive planning time. However, tumor size and variations in adjacent OAR among patients are not considered. Thus, the treatment cannot be individualized. As a result, tumor control rates are decreased in large tumors and sideeffects are increased in small tumors [28, 29]. In BRA, USG can be performed through both transabdominal and transrectal routes [30]. The advantages of both USG techniques are that they are economical, widely availability, portable, and have real-time applicability in the BRA room with relatively short application times. However, neither approach can assess target volume coverage, OAR, residual tumor, vaginal extension, or cumulative dose to the sigmoid colon. Therefore, if USG is used for planning, MRI should be performed to characterize the cervical tumor before RT. In addition, both USG techniques require operator experience and expertise [28, 31]. CTbased BRA planning is increasingly being implemented due to the use of CT-simulators for 3D-CRT in radiation oncology departments. Thus, delineation of the target volumes in consideration of at risk organs, and determining the accuracy of applicator placement, improves local control and survival without increasing acute and late morbidity. However, the most important disadvantage of CT is that it cannot adequately demonstrate the cervical tumor, including vaginal and parametrial extension [32]. Therefore, despite there being no difference between CTand MRI-based delineation of at-risk organs, MRI is the gold standard 3D-imaging technique because it is optimal for soft tissue delineation for cervix uteri carcinoma, including primary tumor and soft tissue invasion. MRI is not routinely available in radiation oncology departments and requires specific applicators. CT-based BRA planning may involve only MRI fusion for planning, or post-EBRT 
pelvic MRI fusion for pre-planning [33, 34]. Second, BRA can be applied at an low dose rate (LDR) or HDR. Due to the disadvantages of LDR-BRA, such as radiation exposure to medical personnel, long treatment duration, and pulmonary embolism risk due to the long hospitalization, HDR-BRA has become widespread given that it has similar survival, recurrence and toxicity rates [35]. In addition, a wide range of applicators are used in BRA. The choice of the applicator depends on the anatomy of the individual patient and the tumor characteristics. The most commonly used applicators are tandem ovoid (TO) applicators with vaginal packing, and TR applicators with a rectal retractor. While there is no difference in tumor treatment outcomes between the two types of applicator, the radiation to which normal tissues are exposed is higher with the TO. The radiation dose to the rectum decreases by $12 \%$ using vaginal packing in TO. However, reports showed that the rectal retractor decreased the radiation dose to the rectum more so than did vaginal packing. Therefore, TR should be used with the rectal retractor if the patient anatomy and tumor characteristics are appropriate [36, 37]. In our study, 3-D conformal and HDR brachytherapy was applied with tandem and ring applicators to all patients.

Prognostic factors for survival include the FIGO stage, the presence of lymph node metastasis, D90 (EQD2) dose, and the HR-CTV. The 3-year OS and PFS were better for FIGO stages IB-IIB (OS $=83 \%$, PFS $=87 \%$ ) than IIIA-IVA (OS $=46 \%$, PFS $=42 \%)$, and for lymph node-negative $(\mathrm{OS}=77-92 \%$ and $\mathrm{PFS}=85 \%)$ versus -positive status $(\mathrm{OS}=50-72 \%, \mathrm{PFS}=53 \%)[38,39]$. Improved 3-year local control rates were reported with $\geq 87$ Gy doses of D90-HR-CTV ( $96 \%$ vs. $80 \%$ for D90HR-CTV $<87$ Gy) and with $\leq 30 \mathrm{~cm}^{3}$ or smaller HR-CTV volumes ( $92 \%$ vs. $72 \%$ for $>30 \mathrm{~cm}^{3}$ volumes) $[40,41]$. In our study, the most important prognostic factor was FIGO stage and 3-year LRFFS rate was found better with $>90$ Gy doses of D90-HR-CTV (100\% vs. $65 \%$ for D 90 HR-CTV $\leq 90$ Gy; $P=0.01$ ).

Comparing image-guided BRA (IGA-BRA) and conventional BRA, survival improved with the former (3year $\mathrm{OS}=86 \%$ vs. $51 \%$, respectively) and grade 3 or higher late toxicity decreased ( $8 \%$ vs. $15 \%$, respectively) [42]. According to the IGA-BRA trials, the 3-year PFS, OS, and late toxicity rates are $65-86 \%, 74-87 \%$, and $5-$ $9.5 \%$, respectively. Lastly, the majority of deaths in patients with cervix uteri cancer after radical RT are due to distant metastases [38, 39, 42-44]. In our study with using three dimensional conformal BRA; the 3-year overall survival was $76.9 \%$ and distant metastasis was the most common cause of death. These findings were consistent with the literature.

In the present study, we reported image-guided radical RT results in patients with LACC drawn from the middle Black Sea region of Turkey. To the best of our knowledge, this is the first Turkish study using both EBRT and intracavitary BRA image-guided RT techniques. We found that the most important prognostic factor was the FIGO stage. Our PFS and OS results are consistent with previous reports. Although the rate of late toxicity has been reported to be between 5 and $9.5 \%$, we did not detect any late toxicity in our patients. In addition, as in previous reports, distant metastasis was the most common cause of death in patients with LACC despite radical RT.

Limitations of the present study included its retrospective nature, single institution design, small number of patients, and short follow-up time.

\section{Conclusions}

Cervix uteri carcinoma was diagnosed in the advanced stage in our patients from the Black Sea region of Turkey, typical of developing countries. However, the treatment and survival outcomes were as good as those in developed countries because treatment involved both image-guided 3-D EBRT and intracavitary BRA. Recurrence was mostly in the form of distant metastases and further investigations on systemic therapies are required.

\begin{abstract}
Abbreviations
3D: Three dimensional; BRA: Brachytherapy; CHT: Chemotherapy; $\mathrm{CrCl}$ : Creatinine clearance; CRT: Conformal radiotherapy; CT: Computed tomography; CTV: Clinical target volume; DDP: Cisplatin; DMFS: Distant metastasis-free survival; EBRT: External beam radiotherapy; EORTC: European Organization for Research and Treatment of Cancer; FIGO: Fédération Internationale de Gynécologie et d'Obstétrique; GEC-ESTRO: Groupe Européen de Curiethérapie and the European Society for Radiotherapy and Oncology; GIS: Gastrointestinal system; GTV: Gross tumor volume; GUS: Genitourinary system; HDR: High dose rate; HR-CTV: High-risk clinical target volume; IGA: Image guided; LACC: Locally advanced cervix uteri carcinoma; LDR: Low dose rate; LRFFS: Locoregional failure-free survival; MRI: Magnetic resonance imaging; NCCN: National Comprehensive Cancer Network; OAR: Organs at risk; OS: Overall survival; PET-CT: Positron emission tomography-computed tomography; PFS: Progression-free survival; PTV: Planning target volume; RT: Radiotherapy; RTOG: Radiation Therapy Oncology Group; TO: Tandem ovoid; TR: Tandem ring; USG: Ultrasonography
\end{abstract}

\section{Acknowledgements}

Not applicable.

\section{Authors' contributions}

AS and BG were responsible for overall study concept. AS, BG, DM and NOO were responsible for treatments. AS, BG, DM and NOO collected the clinical data. AS and BG contributed to the statistical analyses. AS, BG, DM and NOO provided technical and material support. AS and BG analyzed the data, performed the statistical analyses, and wrote the manuscript. All authors reviewed, edited, and approved the final manuscript.

\section{Funding}

Not applicable.

\section{Availability of data and materials}

The datasets used and analyzed during the current study are available from the corresponding author on reasonable request. 


\section{Ethics approval and consent to participate}

This study was approved by the local Ethics Committee of Ondokuz Mayis University Hospital, Samsun, Turkey (acceptance date: 22/6/2017; and number: 2017/256), and all patients provided written inform consent.

\section{Consent for publication}

Not applicable.

\section{Competing interests}

The authors declare that they have no competing interests.

Received: 2 March 2019 Accepted: 26 November 2019 Published online: 12 December 2019

\section{References}

1. Ferlay J, Soerjomataram I, Dikshit R, Eser S, Mathers C, Rebelo M, et al. Cancer incidence and mortality worldwide: sources, methods and major patterns in GLOBOCAN 2012. Int J Cancer. 2015;136(5):E359-86.

2. Miglierini P, Malhaire JP, Goasduff G, Miranda O, Pradier O. Cervix cancer brachytherapy: high dose rate. Cancer Radiother. 2014;18(5-6):452-7.

3. Turkish Cancer Statistic Database. Department of Cancer, Turkish Ministry of Health, 2014, p. 16-40.

4. Giordano L, Bisanti L, Salamina G, Ancelle Park R, Sancho-Garnier H, Espinas $J$, et al. Euromed Cancer working group. The EUROMED CANCER network: state-of-art of cancer screening programmes in non-EU Mediterranean countries. Eur J Pub Health. 2016;26(1):83-9.

5. Shrivastava S, Mahantshetty U, Engineer R, Tongaonkar H, Kulkarni J, Dinshaw K. Treatment and outcome in cancer cervix patients treated between 1979 and 1994: a single institutional experience. J Cancer Res Ther. 2013;9(4):672-9

6. Tharavichitkul E, Chakrabandhu S, Wanwilairat S, Tippanya D, Nobnop W, Pukanhaphan $\mathrm{N}$, et al. Intermediate-term results of image-guided brachytherapy and high-technology external beam radiotherapy in cervical cancer: Chiang Mai University experience. Gynecol Oncol. 2013;130:81-5.

7. Keys HM, Bundy BN, Stehman FB, Muderspach LI, Chafe WE, Suggs CL 3rd, et al. Cisplatin, radiation, and adjuvant hysterectomy compared with radiation and adjuvant hysterectomy for bulky stage IB cervical carcinoma. N Engl J Med. 1999;340(15):1154-61.

8. Morris M, Eifel PJ, Lu J, Grigsby PW, Levenback C, Stevens RE, et al. Pelvic radiation with concurrent chemotherapy compared with pelvic and Paraaortic radiation for high-risk cervical cancer. N Engl J Med. 1999;340(15): 1137-43.

9. Peters WA 3rd, Liu PY, Barrett RJ 2nd, Stock RJ, Monk BJ, Berek JS, et al. Concurrent chemotherapy and pelvic radiation therapy compared with pelvic radiation therapy alone as adjuvant therapy after radical surgery in high-risk early-stage cancer of the cervix. J Clin Oncol. 2000;18(8):1606-13.

10. Rose PG, Bundy BN, Watkins EB, Thigpen JT, Deppe G, Maiman MA, et al. Concurrent cisplatin-based radiotherapy and chemotherapy for locally advanced cervical cancer. N Engl J Med. 1999;340(15):1144-53.

11. Whitney CW, Sause W, Bundy BN, Malfetano JH, Hannigan EV, Fowler WC Jr, et al. Randomized comparison of fluorouracil plus cisplatin versus hydroxyurea as an adjunct to radiation therapy in stage IIB-IVA carcinoma of the cervix with negative Para-aortic lymph nodes: a gynecologic oncology group and southwest oncology group study. J Clin Oncol. 1999;17(5):1339-48.

12. Akkas BE, Demirel BB, Vural GU. Clinical impact of ${ }^{18} \mathrm{~F}-\mathrm{FDG}$ PET/CT in the pretreatment evaluation of patients with locally advanced cervical carcinoma. Nucl Med Commun. 2012;33(10):1081-8.

13. Kusmirek J, Robbins J, Allen H, Barroilhet L, Anderson B, Sadowski EA. PET/ $\mathrm{CT}$ and MRI in the imaging assessment of cervical cancer. Abdom Imaging. 2015;40(7):2486-511

14. Prasad TV, Thulkar S, Hari S, Sharma DN, Kumar S. Role of computed tomography (CT) scan in staging of cervical carcinoma. Indian J Med Res. 2014;139(5):714-9.

15. Narayan K, Lin MY. Staging for cervix cancer: role of radiology, surgery and clinical assessment. Best Pract Res Clin Obstet Gynaecol. 2015;29(6):833-44.

16. Guy JB, Falk AT, Auberdiac P, Cartier L, Vallard A, Ollier E, et al. Dosimetric study of volumetric arc modulation with RapidArc and intensity-modulated radiotherapy in patients with cervical cancer and comparison with 3dimensional conformal technique for definitive radiotherapy in patients with cervical cancer. Med Dosim. 2016;41(1):9-14.
17. Naik A, Gurjar OP, Gupta KL, Singh K, Nag P, Bhandari V. Comparison of dosimetric parameters and acute toxicity of intensity-modulated and threedimensional radiotherapy in patients with cervix carcinoma: a randomized prospective study. Cancer Radiother. 2016;20(5):370-6.

18. Lan ML, Yu X, Xiao H, Zhou P, Hu N, Li J, et al. Clinical outcomes and toxicity of postoperative intensity-modulated versus three-dimensional conformal radiation therapy in patients with cervical cancer. Asia Pac J Clin Oncol. 2016;12(4):430-6.

19. Lv Y, Wang F, Yang L, Sun G. Intensity-modulated whole pelvic radiotherapy provides effective dosimetric outcomes for cervical cancer treatment with lower toxicities. Cancer Radiother. 2014;18(8):745-52.

20. Kidd EA, Siegel BA, Dehdashti F, Rader JS, Mutic S, Mutch DG, et al. Clinical outcomes of definitive intensity-modulated radiation therapy with fluorodeoxyglucose-positron emission tomography simulation in patients with locally advanced cervical cancer. Int J Radiat Oncol Biol Phys. 2010; 77(4):1085-91

21. Yu C, Zhu W, Ji Y, Guo J, Pan P, Han J, et al. A comparative study of intensity-modulated radiotherapy and standard radiation field with concurrent chemotherapy for local advanced cervical cancer. Eur J Gynaecol Oncol. 2015;36(3):278-82.

22. Gandhi AK, Sharma DN, Rath GK, Julka PK, Subramani V, Sharma S, et al. Early clinical outcomes and toxicity of intensity modulated versus conventional pelvic radiation therapy for locally advanced cervix carcinoma: a prospective randomized study. Int J Radiat Oncol Biol Phys. 2013;87(3):542-8.

23. Sonoda K, Yahata H, Ichinoe A, Okugawa E, Kawano Y, et al. Retrospective analysis of concurrent Chemoradiation with triweekly Cisplatin plus 5fluorouracil versus weekly Cisplatin in cervical Cancer. Anticancer Res. 2015:35(6):3447-54.

24. Chen X, Zou H, Li H, Lin R, Su M, Zhang W, et al. Weekly versus triweekly Cisplatin-based chemotherapy concurrent with radiotherapy in the treatment of cervical Cancer: a meta-analysis. Int J Gynecol Cancer. 2017;27(2):344-9.

25. Kinjyo Y, Nagai Y, Toita T, Kudaka W, Ariga T, Shimoji Y, et al. Concurrent weekly cisplatin versus triweekly cisplatin with radiotherapy for locally advanced squamous-cell carcinoma of the cervix: a retrospective analysis from a single institution. Br J Radiol. 2017;90(1076):20170241.

26. Xue $\mathrm{R}, \mathrm{Cai} \mathrm{X}, \mathrm{Xu} \mathrm{H}, \mathrm{Wu} \mathrm{S}$, Huang $\mathrm{H}$. The efficacy of concurrent weekly carboplatin with radiotherapy in the treatment of cervical cancer: a metaanalysis. Gynecol Oncol. 2018;150(3):412-9.

27. Banerjee R, Kamrava M. Brachytherapy in the treatment of cervical cancer: a review. Int J Women's Health. 2014;6:555-64.

28. Tharavichitkul E, Tippanya D, Jayavasti R, Chakrabandhu S, Klunklin P, Onchan W, et al. Two-year results of transabdominal ultrasound-guided brachytherapy for cervical cancer. Brachytherapy. 2015;14(2):238-44.

29. D'Souza D, Baldassarre F, Morton G, Falkson C, Batchelar D. Imaging technologies for high dose rate brachytherapy for cervical cancer: a systematic review. Clin Oncol (R Coll Radiol). 2011;23(7):460-75.

30. vanDyk MS, Schneider Kondalsamy-Chennakesavan S, Bernshaw D, Narayan K. Ultrasound use in gynecologic brachytherapy: time to focus the beam. Brachytherapy. 2015;14(3):390-400.

31. Nesvacil N, Schmid MP, Pötter R, Kronreif G, Kirisits C. Combining transrectal ultrasound and $\mathrm{CT}$ for image-guided adaptive brachytherapy of cervical cancer: proof of concept. Brachytherapy. 2016;15(6):839-44.

32. Harkenrider MM, Shea SM, Wood AM, Chinsky B, Bajaj A, Mysz M, et al. How one institution overcame the challenges to start an MRI-based brachytherapy program for cervical cancer. J Contemp Brachytherapy. 2017;9(2):177-86

33. Dolezel M, Odrazka K, Zizka J, Vanasek J, Kohlova T, Kroulik T, et al. MRIbased preplanning using $C T$ and MRI data fusion in patients with cervical cancer treated with 3D-based brachytherapy: feasibility and accuracy study. Int J Radiat Oncol Biol Phys. 2012;84(1):146-52.

34. Eskander RN, Scanderbeg D, Saenz CC, Brown M, Yashar C. Comparison of computed tomography and magnetic resonance imaging in cervical cancer brachytherapy target and normal tissue contouring. Int I Gynecol Cancer. 2010;20(1):47-53.

35. Lee KK, Lee JY, Nam JM, Kim CB, Park KR. High-dose-rate vs. low-dose-rate intracavitary brachytherapy for carcinoma of the uterine cervix: systematic review and meta-analysis. Brachytherapy. 2015;14(4):449-57.

36. Ma JK, Mourad WF, Allbright R, Packianathan S, Harrell LM, Chinchar E, et al. Short-term clinical outcome and dosimetric comparison of tandem and ring versus tandem and ovoids intracavitary applicators. J Contemp Brachytherapy. 2015;7(3):218-23. 
37. Gaudet M, Lim P, Yuen C, Zhang S, Spadinger I, Dubash R, et al. Comparative analysis of rectal dose parameters in image-guided high-doserate brachytherapy for cervical cancer with and without a rectal retractor. Brachytherapy. 2014;13(3):257-62.

38. Nomden CN, de Leeuw AA, Roesink JM, Tersteeg RJ, Moerland MA, Witteveen PO, et al. Clinical outcome and dosimetric parameters of chemoradiation including MRI guided adaptive brachytherapy with tandem-ovoid applicators for cervical cancer patients: a single institution experience. Radiother Oncol. 2013;107(1):69-74.

39. Lakosi F, de Cuypere M, Viet Nguyen P, Jansen N, Warlimont B, Gulyban A, et al. Clinical efficacy and toxicity of radio-chemotherapy and magnetic resonance imaging-guided brachytherapy for locally advanced cervical cancer patients: a mono-institutional experience. Acta Oncol. 2015;54(9): 1558-66.

40. Dimopoulos JC, Lang S, Kirisits C, Fidarova EF, Berger D, Georg P, et al. Dose-volume histogram parameters and local tumor control in magnetic resonance image-guided cervical cancer brachytherapy. Int J Radiat Oncol Biol Phys. 2009;75(1):56-63.

41. Mazeron R, Gouy S, Escande A, Dumas I, Rivin Del Campo E, Bentivegna E, et al. Locally advanced cervical cancer: is it relevant to report image-guided adaptive brachytherapy using point a dose? Brachytherapy. 2017;16(4):862-9.

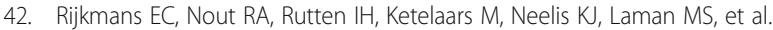
Improved survival of patients with cervical cancer treated with imageguided brachytherapy compared with conventional brachytherapy. Gynecol Oncol. 2014;135(2):231-8.

43. Pötter R, Georg P, Dimopoulos JC, Grimm M, Berger D, Nesvacil N, et al. Clinical outcome of protocol based image (MRI) guided adaptive brachytherapy combined with 3D conformal radiotherapy with or without chemotherapy in patients with locally advanced cervical cancer. Radiother Oncol. 2011;100(1):116-23.

44. Lindegaard JC, Fokdal LU, Nielsen SK, Juul-Christensen J, Tanderup K. MRIguided adaptive radiotherapy in locally advanced cervical cancer from a Nordic perspective. Acta Oncol. 2013:52(7):1510-9.

\section{Publisher's Note}

Springer Nature remains neutral with regard to jurisdictional claims in published maps and institutional affiliations.

Ready to submit your research? Choose BMC and benefit from:

- fast, convenient online submission

- thorough peer review by experienced researchers in your field

- rapid publication on acceptance

- support for research data, including large and complex data types

- gold Open Access which fosters wider collaboration and increased citations

- maximum visibility for your research: over $100 \mathrm{M}$ website views per year

At $\mathrm{BMC}$, research is always in progress.

Learn more biomedcentral.com/submissions 